\title{
Os Desafios do Acesso à Informação e o Controle Social no Estado Pós-Democrático: normalidade ou exceção?
}

\author{
The Challenges of Right to Information and Social Control in the Post- \\ Democratic State: normality or exception?
}

\author{
Caroline Müller Bitencourt ${ }^{1}$ \\ Janriê Rodrigues Reck ${ }^{1}$ \\ ${ }^{1}$ Universidade de Santa Cruz do Sul, Santa Cruz do Sul, RS, Brasil
}

\begin{abstract}
Resumo: O presente trabalho faz uma investigação das relações entre neoliberalismo, Estado de Exceção e controle social na contemporaneidade do Brasil. Assim, o problema que move este artigo se coloca: diante dos elementos de exceção e de neoliberalismo, pode-se dizer que o controle social da Administração Pública já se constitui uma mera ideia vazia de significado? A hipótese é a de que sim, é possível falar em decadência do controle social, principalmente por meio de um de seus principais mecanismos, o acesso à informação. O método de trabalho é o hipotético-dedutivo, testando-se a hipótese a partir da argumentação desenvolvida.
\end{abstract}

Palavras-chave: Neoliberalismo. Estado de Exceção. Controle Social.
Abstract: The present work deals with an investigation of the relations between neoliberalism, the State of Exception and social control in contemporary Brazil. Thus, the problem that moves this article arises: in the face of elements of exception and neoliberalism, can it be said that social control is already a myth, a mere empty idea of meaning? The hypothesis is that yes, it is already possible to talk about the decay of social control, mainly through one of its main mechanisms, access to information. The working method is the hypothetical deductive, testing the hypothesis based on the arguments developed.

Keywords: Neoliberalism. State of Exception. Social Control.

Recebido em: 17/01/2020

Revisado em: 25/04/2020

Aprovado em: 1\%05/2020 


\section{Introdução}

Este trabalho tem por tema as interações entre cultura pós-moderna, Estado de Exceção, neoliberalismo e controle social da Administração Pública. Delimita-se o trabalho temporalmente na experiência contemporânea e espacialmente no contexto ocidental.

A indagação fundamental é: no Estado Democrático de Direito, o acesso à informação e o controle social, diante do contraste de sua posição formal e as reais possibilidades de controle, já poderia ser considerada um "símbolo", um elemento retórico vazio? Qual seria o papel simbólico do controle social e espaço no Estado Pós-Democrático, assim como as consequências deste modelo ao núcleo do controle?

Antes, porém, de conceituar o Estado Pós-Democrático, é importante lembrar que, há bastante tempo, já é campo fértil de investigação para a sociologia a chamada era da Pós-Modernidade. Os indivíduos, nessa era, segundo Bauman (1998), entenderiam como desejável a diferença, reconhecendo diferentes concepções de mundo e cultura. A era das grandes narrativas - um dos poucos elementos comuns ao medievo e à modernidade - é enterrada de vez. A superindividuação - elemento compartilhado por diversas tendências políticas, à esquerda e à direita, é fenômeno que desenvolveu uma mentalidade onde viver e lidar com estranhos, com o diferente, é mantê-los à parte, isolá-los. Essa maximização da autodeterminação, fruto de uma longa caminhada de um processo de "reapoderamento" humano, acaba por se converter, paradoxalmente, em "desapoderamento", e a proposta da modernidade de emancipação em uma nova opressão.

Nessa perspectiva, a promessa de ampliação das liberdades na pós-modernidade não se converteu em ampliação, mas em uma forma de redistribuição polarizada de diferenças estereotipadas. Essa forma “[...] intensifica-se entre os alegres e solicitamente seduzidos, enquanto aguça quase que para além da existência entre os despojados e panopticamente dirigidos" (BAUMAN, 1998, p. 47). Assim, de um lado, a estranheza fica sendo fonte de agradável de experiência e de satisfação estética, e, de outro, "[...] como aterradora da corporificação da viscosidade desabridamente ascensional da condição humana, e como efígie para toda a futura 
calcificação do ritual de seus horrores" (BAUMAN, 1998, p. 47). A política da exclusão origina-se na lógica da polarização, e o individualismo induz à ideia de que há duas nações diferentes e incompatíveis entre si (BAUMAN, 1998, p. 47).

Assim, para resolver a hipótese, em um primeiro momento, serão abordados os principais elementos do neoliberalismo para, em seguida, conectar esses elementos com o Estado de Exceção e, finalmente, verificar o resultado à luz das sucessivas limitações ao direito de informação emitidas pelo Poder Executivo em 2019 e 2020.

Justifica-se cientificamente o projeto diante da necessidade de estudos conectando os diversos elementos culturais existentes ao problema do controle social - problema até então pouco explorado. Ainda, socialmente, dado que o controle social da Administração Pública é um dos elementos centrais da Democracia, as restrições impostas pelo Estado de Exceção ao controle social merecem a máxima atenção. Os temas do controle social e do Estado de exceção fazem parte das preocupações epistemológicas e acadêmicas de ambos autores, os quais desenvolvem projeto de pesquisa na instituição de filiação.

Finalmente, em termos de método de pesquisa, foi adotado o tipo hipotético-dedutivo, com a formulação da hipótese de resolução do problema - já há prejuízos advindos da exceção ao controle - e seu teste argumentativo.

\section{Elementos Culturais do Neoliberalismo}

A liquidez dos valores, das relações e dos prazeres conduz a uma busca pela satisfação imediata, e o consumo passa a ser fonte de felicidade (pseudofelicidade). As novas configurações de exploração atingem um ponto alto e surpreendente. O homem não é só vendido a outro ou ao sistema, vende-se a si mesmo e explora a si mesmo. Essa autoexploração vem a custo de depressão socialmente generalizada, e os sujeitos estão encerrados em mecanismos prisionais, de desemprego, de consumo, pelo padrão estético, pelos inimigos que são criados a partir das diferenças. De todo modo, essa autoexploração em busca do máximo de desempenho encontra obstá- 
culos administrativos relativos ao interesse público. O interesse público é, assim, um obstáculo à autoexploração. Mas o indivíduo hiper e autoexplorado quer distância de qualquer regulamentação, não mostra interesse pela coisa pública e não compartilha do desejo de participação.

Ao mesmo tempo em que parte da população vive em uma louca busca de desempenho, outra parte vive em desalento e prostração; e, ainda, há aqueles que oscilam entre um campo e outro, mas, em comum, é possível perceber: um movimento em prol do antipolítico (tudo que está relacionado à administração pública não presta) ou apolítico (o que tem relação com a política não interessa ao indivíduo). O desalento e a prostração estão conectados tanto com uma realidade de falta de solidariedade social, serviços públicos e oportunidades, como também com a formação de expectativas bem ancoradas na realidade de que não existem alternativas. Isso reflete em pouca disposição tanto para seguir normas de Direito Administrativo como para participar na formação deste, em conhecer e controlar as decisões administrativas, em participar da vida pública e da gestão dos seus interesses.

Já o hiperindividualismo reflete a exponencialidade desesperada do egocentrismo. A sociedade líquida contemporânea confirmou que a fórmula individualista não produz mais bem-estar; a resposta cultural foi, contudo, mais egocentrismo, em suas diversas matrizes e conexões (como a pós-verdade e o neoliberalismo). Esse egocentrismo resiste, em todas as suas forças, a esquemas jurídicos voltados ao interesse público de modo que se enfraquecem todos os institutos de Direito Administrativo, até mesmo o poder de polícia, já que este implica a imposição de limites.

$\mathrm{O}$ individualismo gera sociedades e indivíduos que não só duvidam de fatos, mas não que não querem tornar suas vidas mais complexas e ricas com elementos culturais que não sejam derivados do consumo. Se uma mera vontade caótica basta, para que duvidar, estudar e comungar? Academias e organizações administrativas refletem a pobreza intelectual, e poucas alternativas e espaços de resistência são gerados. Novamente, desprestígio do Direito Administrativo.

Essa sociedade e esse indivíduo pós-modernos encontram-se num sistema de organização Estatal sujeito ao dever ser da opção constitucio- 
nal de cada Estado-Nação. O Estado, portanto, recebe o atributo de direito, pois está sujeito ao império da legalidade e à perspectiva democrática por pressupor a legitimidade a partir da gestão compartilhada com a participação popular da administração do interesse público. Todas as situações de polarização, exclusão e inclusão, liberdades individuais e direitos coletivos que envolvem o homem Pós-Moderno dependem de sua garantia e positivação nos Estados Democráticos, especialmente a partir do Direito Administrativo, que é o responsável pela prestação de serviços e promoção tanto de igualdades quanto do respeito das diferenças. Os mecanismos de combatê-las são as políticas públicas. É dever do Estado produzir a informação pública nesse ambiente. Esse é o motivo que se torna tão relevante o estudo do que se chama de Estado Pós- Democrático: dele depende a forma de garantia dos direitos, conquistas e uma possível resistência ao declínio e retrocesso social. Mas não é esse o caminho que parece que vamos percorrer, afinal

[...] as estruturas sociais que estão sendo erigidas, com o desmonte estatal e a globalização, não estão propiciando a humanidade o desabrochar do homem solidário, amoroso e orientado para a livre manifestação da vida em todas as suas formas, antes pelo contrário [...]. (NOHARA, 2012, p. 110)

Para Saddy (2018), sob uma perspectiva distinta, a nova configuração contemporânea designada como Estado Pós-Moderno caracterizaria a reformulação do aparato estatal abrangendo distintas damas de Estado, mas que se unem na perspectiva de quatro segmentos: 1) o fortalecimento dos laços de interdependência, afinal o processo de modernização do estado passaria por processos que reduzem a margem de liberdade dos Estados e favorecem o surgimento de novos atores sociais e a intensificação dos laços de interdependência e solidariedade; 2) redefinição das funções estatais, consagrando um regime de mercado operado pelo tipo liberal do processo econômico, que admite a intervenção do Estado apenas no sentido de coibir abusos e preservar a livre concorrência, determinando que atividades devem ser desenvolvidas pela iniciativa privada, por força tanto da abstenção do Estado quanto pelo princípio da subsidiariedade, pois se vê obrigada a relação com os novos atores internos e externos - 
abandonando o papel de Estado prestador para Estado protetor; 3) mitigação das especificidades estatais, um estado desmitigado que construir sua legitimidade com base no "mito" do interesse público e a distinção entre público/privado que deu azo a dois sistemas de valores com normas distintas (público por interesse púbico e privada por interesse privado), a ideia que a administração pública seja como o privado no que concerne métodos de gestão a fim de atingir uma administração de resultado; e 4) possui relação com a fragmentação da estrutura estatal, no sentido que a burocracia antes fundada na base da hierarquização é desestabilizada pela proliferação de estruturas de outro tipo, caracterizando uma complexidade e diversidade de distintos centros de poder. Nas palavras do autor: "[...] nesse panorama atual, pode-se dizer que o Estado passou a intervir em uma maneira muito mais equilibrada na economia" (SADDY, 2018, p. 150).

O modelo de Estado Democrático de Direito, como opção política e jurídica da sociedade, teria como principal compromisso a realização dos direitos fundamentais e tem como principal característica a existência de limites legais ao exercício do poder, de qualquer poder, diga-se de passagem, pois a ideia de controle é ínsita ou mesmo anterior a sua própria existência, e é também aquilo que o justifica. A limitação e vinculação à lei e a normatividade constitucional seriam suas marcas na modernidade. Se há divergentes perspectivas quanto ao paradigma do Estado Pós-Moderno é ponto praticamente pacífico na doutrina que a caracterização do modelo de Estado Democrático de Direito, enquanto opção política e jurídica da sociedade, teria como principal compromisso a realização dos direitos fundamentais e tem como principal característica a existência de limites legais ao exercício do poder, de qualquer poder, pois a ideia de controle é ínsita ou mesmo anterior a sua própria existência, é também aquilo que o justifica. $\mathrm{O}$ embate é sempre relacionado sobre qual a melhor forma de o direito administrativo concretizá-la, aí entra a discussão quanto aos responsáveis pela prestação do serviço, aos atores envolvidos e suas respectivas responsabilizações, o regime jurídico e os compromissos adotados e sua submissão ao controle. A limitação e vinculação à lei e a normatividade constitucional seriam suas marcas, independente se o Estado prestaria diretamente ou não o serviço. Claro que tudo sob o aspecto teórico, sabe-se que a práxis não é tão simples assim. 
Já em relação ao Estado Pós-Democrático, muitas são as características atribuídas a ele ${ }^{1}$, lembrando que a expressão "Estado Pós-Democrático", no caso brasileiro, ficou marcada pela obra de Rubens Casara (2017). Uma importante característica dessa noção de Estado Pós-Democrático é a conotação atribuída ao termo "crise", que, por definição, poderia ser tido como algo excepcional, algo que justifica medidas mais extremistas, colocando em xeque o sistema, como algo que ainda pode ser salvo, como um problema que ainda pode ser superado. Por outro lado, o termo atribui algo de normalidade também. Quem não viveu alguma “crise" e já a superou? No entanto, a expressão "crise" ligada à característica do Estado não tem sido superada; a crise é uma constância, um estado permanente de coisas, uma crise que é útil a um determinado status quo da sociedade e que reproduz um sistema que "serve a muitos senhores", então, seria mesmo uma crise? Essa crise justificaria a eliminação dos limites constitucionalmente impostos, ainda que se faça em nome da própria Constituição, e é possível, em nome da superação da crise, a violação de direitos fundamentais, ou, em nome do discurso de preservação da ordem constitucional, violar a ela própria? Para Casara, a resposta é simples: "[...] o que chamam de 'crise' é, na verdade, um modo de governar as pessoas" (CASARA, 2017, p. 16).

Analisando-se crítica e atentamente o que caracteriza o Estado Pós-Democrático, não há como negar, a partir da exposição de Casara, que o Estado Pós-Democrático ou é ou mantém um "flerte" com o Estado de Exceção.

\section{Estado de Exceção no Contexto Neoliberal Brasileiro}

Para Rafael Valim (2017), a partir da obra de François Saint-Bonnet, haveria duas formas de identificar o vocábulo "exceção". A primeira acepção era empregada para designar a necessidade de suspensão tempo-

\footnotetext{
${ }^{1} \mathrm{O}$ autor utiliza o termo com consciência das inúmeras restrições existente ao termo "pós" para designar algo, como a próprio leitura de abandono do Estado, mas, ao longo do texto, justifica a necessidade de utilizar essa expressão para não encontrou outra que designe as características que o identifiquem.
} 
rária das regras jurídicas ou mesmo sua transgressão para enfrentar algo que se coloca como perigo. Já a segunda seria um sentido explorado a partir da expressão da obra de Agamben e corresponderia a uma transformação de certos institutos jurídicos em face de perigos permanentes, trazendo um novo paradigma de governo, como ocorreria no enfretamento contra o terrorismo. Nesse sentido, não haveria expressão mais correta ou adequada, e há sim que compreender o ponto de partida para saber em qual situação se encaixa a expressão (VALIM, 2017, p. 21).

Haveria, a depender da dimensão do conhecimento, três distintas observações para designar a "exceção". A primeira, nas lições da Sociologia, revela as ambiguidades de Estado que se proclamam de Direito, entre os quais uma camada da população nunca teve acesso a suas garantias, pois se instauram regimes de terror: negros, árabes, curdos, judeus, homossexuais, travestis, operários morrem e nascem todos os dias sem conhecer o comedimento do Estado e suas garantias. Já na teoria política, a exceção é um paradigma de governo na contemporaneidade, e todas as violências são cometidas em nome do Estado para se justificar o estado de crise permanente. Por fim, no sentido filosófico, estaria o decisionismo de Carl Schmitt, calcado nos elementos soberania, decisão e exceção, para designar que a exceção está calcada no poder soberano de decidir quando ela ocorre ou não (VALIM, 2017, p. 21).

O interesse nesta pesquisa é pela concepção de exceção da ciência política e a forma como ela reproduz reflexões em relação ao controle social e acesso à informação. Dessa forma, este trabalho aproxima-se da expressão cunhada por Giorgio Agamben (2010, p. 18), por suas lições: “[...] o aporte específico do estado de exceção não é tanto a confusão entre os poderes [...] quanto o isolamento da força de lei em relação à lei”. Há duas faces importantes, a norma permanece em vigor, mas não se aplica (em justificativa à exceção); de outro lado, os atos praticados sem respaldo, guarida jurídica, passam a adquirir força de lei. Agamben não tem dúvidas de que o estado de exceção já é um Estado institucionalizado e hoje a situação dos ordenamentos ocidentais é claramente uma divisão: “[...] em ordenamentos que regulam o Estado de exceção na Constituição ou por meio da lei, e os regulamentos que preferem não regulamentar explicitamente o problema" (VALIM, 2017, p. 22). O caso brasileiro é bem 
claro: por um lado, mantêm-se estáticas e intactas as garantias constitucionais; por outro, o Poder Judiciário ${ }^{2}$ e o Ministério Público reiteradamente vêm colocando em prática o Estado de Exceção. Uma tese poderia ser construída com base em cada uma delas, mais aqui se resumem aquelas com impacto violento, como: a reinterpretação da presunção da inocência pelo Supremo Tribunal Federal, a decisão de mandados de busca coletivo e habeas corpus coletivo, a revelação e escutas telefônicas pelo próprio juiz da investigação, a despeito ainda de as provas terem sido obtidas por meios ilícitos e um destaque especial à manifestação do Tribunal Regional da $4^{\text {a }}$ Região, ao afirmar que a operação Lava-Jato não precisa seguir regras comuns processuais, afinal: "trazem problemas inéditos e exigem soluções inéditas"3.

\footnotetext{
${ }^{2}$ Em diversos votos proferidos no STF pelo Ministro Eros Grau, empregou-se a teoria do estado de exceção para justificar a não aplicação de regras constitucionais a casos em que, pelo seu texto, deveriam incidir, mas nos quais a presença de circunstâncias excepcionais justificaria o respectivo afastamento. Algumas dessas decisões poderiam ser explicadas por meio do recurso à ideia de equidade, ao invés da teoria do estado de exceção. Não nos parece apropriado [...] atribuir ao STF o "poder soberano", no sentido de Carl Schmitt, de suspender a força de normas jurídicas para instaurar a exceção. Essa linha argumentativa, além de desnecessária, pode revelar-se perigosa, se manejada por quem não tenha os mesmos compromissos democráticos do Ministro Eros Grau (SARMENTO, 2013. p. 545-546).

3 Manifestação do Tribunal da Região quando arquivou representação contra Sergio Moro, por 13 votos a 1, no qual arbitrariamente revelou escutas telefônicas envolvendo a então Presidente da república Dilma e que posteriormente foram anuladas pelo Supremo Tribunal Federal. Aliás, na decisão, revelaram que a conduta foi "incensurável” do magistrado. Vale a ressalva ao voto divergente do desembargador Rogério Fraveto, divergindo da própria postura em favor do Estado de exceção já invocada pelo então Ministro Eros Grau, destacando-se: Vale dizer que o Poder Judiciário deve deferência aos dispositivos legais constitucionais, sobretudo naquilo em que consagram direitos e garantias fundamentais. Sua não observância em domínio tão delicado como o Direito Penal, evocando a teoria do estado de exceção, pode ser temerária se feita por magistrado sem os mesmos compromissos democráticos do eminente Relator e dos demais membros desta Corte. Pois bem. Compreendo que a análise da deflagração ou não de processo de índole disciplinar no caso passa por dois momentos. Num primeiro momento, cabe verificar se o ato que constitui o cerne da representação - o levantamento de sigilo de conversas telefônicas interceptadas - foi legal ou ilegal. Num segundo momento, se concluído que o ato foi ilegal, impõe-se apreciar se a ilegalidade e as circunstâncias em que se deu são aptas à instauração de processo disciplinar" (CONJUR, 2019).
} 
O que há evidentemente de comum entre os termos Estado Pós-Democrático e Estado de Exceção? As instituições e as garantias constitucionais aparecem aos olhos do "senso comum" intocável, nada formalmente parece indicar a superação do conceito de Estado Democrático de Direito. Assim, cria-se um desmanche do Estado por dentro do próprio Estado e de suas instituições, utiliza-se o discurso dos direitos fundamentais contra os direitos fundamentais, como se houvesse direitos capazes de sobrepor-se aos outros, como se fosse necessário sacrificar alguns direitos em nome de um bem maior, um inimigo desconhecido e implementado no imaginário social.

Característica talvez mais evidente é a constante violação dos limites ao exercício do poder, mas, além disso, é o desaparecimento de qualquer pretensão de fazer valer esses limites. $\mathrm{Na}$ "pós-democracia desaparecem, mais do que a fachada democrática do Estado, os valores democráticos" (CASARA, 2017, p. 21). O autor ainda menciona que o desaparecimento dos valores democráticos se deu em nome da "democracia", eis que se utilizam de uma alegada democracia para ferir a própria democracia (CASARA, 2017, p. 21).

Estado de Exceção e Estado de Direito são categorias que se repelem mutuamente. Valim compreende que a exceção não pode ser tomada exclusivamente em seus aspectos políticos, pois entende que sempre pertencerá ao Direito. Em verdade, compreende que o ordenamento jurídico brasileiro dispõe de conceitos e parâmetros para o exercício de prerrogativas excepcionais, sem que para isso precise lançar mão do Estado de Exceção. Então a conclusão deve ser outra: “[...] que o préstimo da noção de Estado de Exceção não é dogmático-jurídico, senão que de outra natureza [...]" (VALIM, 2017, p. 57).

Outra notável característica associada ao que se pode chamar de "técnicas" de Estado de Exceção é o arquétipo de um grupo marginal, um inimigo interno, ou seja, para desviar a atenção dos problemas reais e externos, como as crises econômicas, as políticas internacionais e nacionais, o desemprego, a produção de riquezas e pobrezas, entre outros. A imagem do inimigo, os cenários de ameaças, a instalação de um clima de hostilidade e insegurança oferecem ao público modelos interpretativos dos con- 
flitos sociais e, ao mesmo tempo, criam a necessidade de apaziguamentos e símbolos autoritativos, ou seja, entre ameaças e apaziguamentos a política do medo produz o desejo por segurança, e as técnicas de precaução justificam a exceção, pouco importando os valores que serão sacrificados em nome desse desejo. Essa precaução carrega em si justificativas de retrocesso em sua qualidade de Estado de Direito, com a perda das liberdades em face do "regime de direito do medo" (FRANKENBERG, 2018).

No Estado Pós-Democrático, que também se caracteriza por ser um Estado sem limites rígidos ao exercício do poder, verifica-se uma aproximação do poder econômico e o poder político, sendo que o modelo econômico fala tanto ou mais alto que a perspectiva constitucional. A Constituição pode se comportar como "inimiga" da nação se, aos olhos do senso comum, representar um empecilho ao desenvolvimento econômico ${ }^{4}$, a exemplo do que ocorre no Brasil em relação à proteção do meio ambiente como uma barreira ao desenvolvimento econômico, proteção da dignidade do trabalhador ser um entrave aos lucros do empresariado, os serviços públicos que garantem as condições de felicidade aos indivíduos na perspectiva social serem vistos em termos de custo para o Estado. Nesse cenário, o encarceramento passa a ser a resposta para os problemas de exclusão e insegurança social, e vê-se na transferência do público para o privado a solução dos problemas de uma democracia.

No Brasil, assistiu-se estarrecido em janeiro de 2019 a homens e mulheres assalariados defendendo o aumento irrisório (praticamente inexistente) do salário mínimo, em nome da defesa de um governo. Uma sociedade em que o acúmulo de capital passa a ser baliza para condição de caráter e juízo moral de uma sociedade certamente é uma sociedade doente. Em uma leitura da condição política, econômica e social deste tempo, Pierre Dardot e Christian Laval fazem um diagnóstico desolador:

\footnotetext{
${ }^{4}$ Muito bem lembrado por Hachem, o desenvolvimento econômico não diz respeito à elevação do produto nacional com o incremento da eficiência do sistema produtivo, vai muito além na medida que existe uma interdependência com a esfera humana e socia, não deve estar vinculado apenas em termos quantitativos, mas sim qualitativos. O desenvolvimento econômico reclama também por estruturais e socioeconômicas com incremento da qualidade de vida, bem-estar e participação social (HACHEM, 2013).
} 
"O sistema neoliberalismo está nos fazendo entrar na era da pós-democracia" (LAVAL; DARDOT, 2016, p. 8). Sobre o tema:

É importante considerar que não se trata, portanto, somente de uma ideologia de natureza econômica. Além da "tese econômica" sobre as finalidades do Estado (centrada na idéia de maior eficiência do mercado), a ideologia neoliberal típica da última transição de século compreende de forma marcante uma "tese moral" (traduzida por uma concepção individualista dos direitos humanos) e uma "tese política" (que valoriza as ações autônomas da sociedade civil como meio de desenvolvimento. (GABARDO, 2009, p. 217)

A obra Pós-Neoliberalismo, Pós-Políticas Sociais e o Estado Democrático (SADER; GENTILI, 2012, p. 32) deixa evidente a capacidade do neoliberalismo como ideologia, sua capacidade de reinvenção e disseminação de suas ideias em todos os continentes e em diferentes segmentos sociais. Para além dos êxitos eleitorais e sua onda de avanço nas últimas décadas, ele ganha impressionante vitaliciedade diante da vulnerabilidade de seus históricos opositores, como a queda do socialismo real, a crise dos Estados de bem-estar, a dessindicalização. Difícil é encontrar freios à altura da retomada do neoliberalismo e suas ideologias após o "colapso do modelo soviético". Para que as alternativas não recaiam em devaneios utópicos, a esquerda também deverá superar suas incapacidades na construção de alternativas.

Assim é que dois conceitos são indissociáveis quando se trata de Estado Pós-Democrático: o neoliberalismo como faceta econômica (e não apenas sua capacidade) transmutou-se também em organização política e sistema normativo; e Pós-democrática enquanto gestão de valores e interesses desse sistema neoliberal. Ao se contextualizar o Estado Pós-Democrático, uma pergunta a ser feita no âmbito desta pesquisa é: qual a influência e os reflexos que o modelo Pós-Democrático (e assim o neoliberalismo e a Pós-Democracia) terão sobre o acesso à informação e o controle social? Sobre o regime de direito administrativo? Nesse sentido, sobre o tema: 
Além dos fatores sociológicos e políticos, os próprios móbeis subjetivos da mobilização são enfraquecidos pelo sistema neoliberal: a ação coletiva se tornou mais difícil, porque os indivíduos são submetidos a um regime de concorrência em todos os níveis. As formas de gestão da empresa, o desemprego, a precariedade, a dívida, a avaliação, são poderosas alavancas de concorrência interindividual e definem novos modos de subjetivação. A polarização entre os que desistem e os que são bem-sucedidos mina a solidariedade e a cidadania. A abstenção eleitoral, a dessindicalização, racismo, tudo parece conduzir à destruição das condições do coletivo e, por consequência, ao enfraquecimento da capacidade de agir contra o neoliberalismo. [...] mas não devemos ignorar as mutações subjetivas provocadas pelo neoliberalismo que operam no sentido do egoísmo social, da negação da solidariedade e da distribuição e que podem desembocar em movimento reacionários ou até mesmo neofacistas. (LAVAL; DARDOT, 2016, p. 9)

Outro termo que está implícito no conceito de Estado Pós-Democrático é também o da pós-democracia. O significante "democracia" não desaparece, mas perde seu conteúdo, é a constituição de uma cidadania alienada a favor do poder econômico, apática, apolítica ou antipolítica, mas, acima de tudo, acrítica. É possível que a democracia não seja a forma de produção da decisão ante o cenário atual, mas apenas o de legitimá-la; há quem defenda, como Levistky e Ziblat (2018), que se vive a morte das democracias, ou, nas palavras de Runciman (2018), o fim das democracias. Isso porque se vive um cenário de demonização da política, ou seja, a política passa a ser percebida como uma negatividade, como aquilo que é corrupto, contraprodutivo. O Estado e a política são vistos como inimigos, como algo que não interessa às pessoas e não como espaços de luta por uma vida mais digna.

Mas é mais do que isso, a política na contemporaneidade vive um "retorno" do populismo, o populismo e seu domínio da política democrática. A ideia básica por detrás do populismo, seja de esquerda ou de direita, é o domínio da democracia pelas elites, de que a democracia fora roubada de seu povo. $\mathrm{Na}$ conversão desse tipo de teoria da conspiração, quando convertida em filosofia de governo, tudo passa a ser colocado em 
cheque: o sistema eleitoral, a validade das urnas, o sistema é manipulado, enfim, o populismo consegue impregnar "[...] a paranoia para todos os lados" (RUNCIMAN, 2018, p. 72-73). No próprio populismo, não há nada de novo, estão sempre presentes, diante das crises econômicas, mudanças tecnológicas, desigualdades crescentes, discursos anticorrupção, diante da insegurança da sociedade, e fomentam a quebra de confiança nas instituições democráticas, apresentando soluções simplistas para problemas altamente complexos. Um discurso de fácil identificação popular.

E qual a relação com o acesso à informação e transparência democrática? A prática democrática de acesso a informações pressupõe interesse pelas questões públicas e busca por informações relacionadas a isso. Entretanto, após, a manifestação de interesse pelo acesso à informação surge um problema: o que fazer com essa informação? As respostas simples comunicadas de maneira rápida, com jargões e discursos que geram aderência, através de meios informais de acesso, produzem efeitos bem mais imediatos e impactantes nessa forma de gestão. Então, por que recorrer a conhecer dados, buscar as fontes, se, em tese, goza-se de meios de informação para isso?

Uma questão produtiva ao debate relaciona-se ao fato de que a era da tecnologia e da sociedade em redes mostrou a incompetência das formas tradicionais de lidar, por exemplo, com as fake news. A verdade não é mais tão importante quanto a sensação de estar informado, de repassar a notícia (pseudonotícia) e isso somente beneficia a manipulação da informação, trabalha contra a transparência e impede um efetivo controle social. Tudo isso coloca também em cheque a democracia:

A democracia não é mais jovem. Não há mais a sensação inebriante que predominava um século atrás, de um potencial vasto e ainda por realizar. As batalhas para aumentar os direitos dos cidadãos já foram travadas e em grande parte vencidas. O Estado arca com a vasta gama de serviços públicos que se espera que ele forneça. Os níveis de dívida pública e privada estão altos [...]. A reação populista que vem acontecendo nas democracias estabelecidas já há um bom tempo. As pessoas estão enfurecidas com as instituições que se mostram incapazes de dar respostas melhores, não porque sejam 
subdesenvolvidas, mas porque estão cansadas. Esse quadro torna ainda mais difícil romper com o ciclo de desconfiança. A democracia não está funcionando bem - se estivesse, não veríamos esse retrocesso populista. (RUNCIMAN, 2018, p. 72-73)

Outra característica do Estado Pós-Democrático - a qual afeta diretamente o acesso à informação e controle social e talvez seja, inclusive, sua característica mais latente - é a constante a violação dos limites ao exercício do poder, mas, além disso, há o desaparecimento de qualquer pretensão de fazer valer esses limites. Na pós-democracia desaparecem, mais do que a fachada democrática do Estado, os valores democráticos. Ironicamente o desaparecimento dos valores democráticos se deu em nome da "democracia", eis que se utilizam de uma alegada democracia para ferir a própria democracia.

"Na pós-democracia não existem obstáculos ao exercício do poder: os direitos e garantias fundamentais também são vistos como mercadorias que alguns consumidores estão autorizados a usar" (CASARA, 2017, p. 41). Disso, resultam os extremos descasos com os serviços públicos e políticas públicas que passam a ser concebidos como verdadeiros "pesos", "atrasados" aos processos econômicos e sociais, e a sociedade passa não apenas a assistir passivamente como a defender o desmanche do Estado como prestador e garantidor dos serviços. Não há como dissociar o Estado Pós-Democrático do sistema neoliberal; o conceito de liberdade toma distanciamento do conceito de igualdade, a "liberdade" passa a ser entendida como a liberdade para ampliar as condições de acumulação do capital e geração de lucros; é apenas uma garantia da propriedade privada, do desenvolvimento econômico distante do desenvolvimento humano (CASARA, 2017, p. 29). Nesse sentido, sobre o tema:

A lógica do Estado Neoliberal será a da insegurança transformada em princípio, a da competição e do risco que premiarão os mais capazes. Se na visão social-democrata o Estado deve dar proteção aos mais fracos ao mesmo tempo em que estimula a competição regulada, reconhecendo, portanto, a relação dialética entre defesa dos interesses individuais e solidariedade em relação aos mais fracos, na visão neoliberal a competição de todos contra todos se torna um 
bem maior. A única proteção que o Estado deve oferecer é a liberal, contra o inimigo externo e contra o crime; é garantir a propriedade e os contratos. Contrariando o processo histórico de busca de segurança razoável, a lógica era a de premiar os mais fortes - os vencedores no mercado. (BRESSER-PEREIRA, 2014, p. 95)

Uma interessante reflexão sobre o futuro do sistema capitalista ou neoliberal como hoje se conhece é apresentada por Paul Mason, na expressão designada pelo autor como "era do Pós-Capitalismo". Seria uma espécie de revolução produzida e conduzida pelo próprio capitalismo, mas potencialmente capaz de destruir a economia e o mercado como se percebe hoje a partir da tecnologia de informação. Uma tentativa que emerge de forma natural como alternativa ao modo de vida capitalista que se experimenta nas últimas décadas, maximizando o poder e o caráter aberto das informações. Acredita-se que seriam cinco os principais preceitos para essa transição: 1) entender as limitações da força de vontade humana em face de um sistema frágil e complexo (a solução seria testar propostas em pequenas escalas, simulando virtualmente impactos macroeconômicos antes de implementá-los - imagine-se isso no campo de políticas públicas); 2) sustentabilidade ecológica (é necessário desenvolver tecnologias, pois os cortes serão em larga escala de impactos ambientais, como falta de energia, migração em massa, etc.); 3) a transição não pode ter exclusiva relação com a economia, há também que ser humanitária (a percepção do ser humano não pode ser resumida à justiça econômica e social e sua força de trabalho, pois todos são amantes, consumidores, comunicadores, por exemplo); 4) atacar o problema a partir de todos os ângulos (com a emergência das redes, a capacidade de ação não pode estar restrita ao Estado, organizações formais, partidos políticos, ou seja, indivíduos e agrupamentos temporários podem ser poderosos nesse processo); e 5) maximizar o poder da informação, pois, através da internet das coisas, haverá um verdadeira incorporação da máquina social, pode-se fluir a informação com facilidade e tecnologia de coleta e captação de dados, impedindo a monopolização e o mau uso da informação pelos Estados, incorporações e grupos organizados. Essa é uma proposta de descentralização do controle, mas com qualidade de informação (MASON, 2018, p. 385-387). 
Por ora, na realidade vivenciada nos contextos políticos atuais, entram em cena velhos e novos mecanismos de concentração dos meios de comunicação de massa, a fabricação de "próteses de pensamento", através de televisores, computadores, smartphones, eletrônicos e o uso exacerbado e sem filtros de redes sociais em que cidadãos são na realidade os consumidores acríticos. Diante do excesso de informação ou a distorção da informação, vê-se crescer de forma quase descontrolada a desinformação (CASARA, 2017, p. 29).

Com base nessas observações, uma é a questão a ser respondida neste cenário atual: quais os desafios do acesso à informação e transparência ante o contexto da pós-verdade, da superinformação e desinformação e de um direito administrativo que se afasta constantemente de seu regime jurídico, no qual o Estado é mau e o privado é bom?

\section{Os Exemplos de Legislação Autoritária Recentes}

Nos anos de 2019 e 2020, o controle social, que pressupõe o acesso à informação, foi atacado duas vezes pelo Poder Executivo, a saber, por meio do Decreto n. 9.690/2019 e pela Medida Provisória n. 928/2020.

O Decreto n. 7.724/2012, alterado pelo Decreto n. 9.690/2019, traz a possibilidade de delegação da competência para o estabelecimento da classificação das informações, a saber:

4 o agente público a que se refere o $\S 3^{\circ}$ dará ciência do ato de classificação à autoridade delegante, no prazo de noventa dias.

Art. 46.

II - Ministério da Justiça e Segurança Pública;

V - Ministério da Economia;

VI - Ministério da Mulher, da Família e dos Direitos Humanos;

VII - Gabinete de Segurança Institucional da Presidência da República; 
VIII - Advocacia-Geral da União; e

IX - Controladoria-Geral da União.

Art. 47

III -

a) pela Controladoria-Geral da União, em grau recursal, a pedido de acesso à informação ou de abertura de base de dados, ou às razões da negativa de acesso à informação ou de abertura de base de dados; ou

(NR)

Art. 69. Compete à Controladoria-Geral da União e ao Ministério da Economia, observadas as competências dos demais órgãos e entidades e as previsões específicas deste Decreto, por meio de ato conjunto:

Art. $2^{\circ}$ Fica revogado o inciso $\mathrm{X}$ do caput do art. 46 do Decreto $\mathrm{n}$. 7.724, de 2012.

A significativa e simbólica alteração relevante para esta pesquisa é a do artigo 30 do Decreto n. 7.724/2012, especialmente dos $\S \S 1^{\circ}, 2^{\circ}$ e $3^{\circ}$. Originariamente, ao trazer a lista das pessoas autorizadas para a competência de agravar as informações secretas e ultrassecretas, estabelecia a impossibilidade de delegação em seu $\S 1^{\circ}$, que na nova redação ficou assim expresso:

$\S 1^{\circ}$ É permitida a delegação da competência de classificação no grau ultrassecreto pelas autoridades a que se refere o inciso I do $c a-$ put para ocupantes de cargos em comissão do Grupo-DAS de nível 101.6 ou superior, ou de hierarquia equivalente, e para os dirigentes máximos de autarquias, de fundações, de empresas públicas e de sociedades de economia mista, vedada a subdelegação.

Também, no $\S 2^{\circ}$, somente era permitida a delegação de competência para informações reservadas, para agentes públicos que exercessem cargos de direção, comando ou chefia; já a atual redação novamente amplia o leque de possibilidades: 
$\S 2^{\circ}$ É permitida a delegação da competência de classificação no grau secreto pelas autoridades a que se referem os incisos I e II do caput para ocupantes de cargos em comissão do Grupo-DAS de nível 101.5 ou superior, ou de hierarquia equivalente, vedada a subdelegação.

A nova redação atribuída ao $\S 3^{\circ}$ permitiu também a delegação à informação considerada a agente público que exerça função de direção, comando ou chefia, vedada a subdelegação.

Duas perguntas são fundamentais a partir do novo Decreto: Qual a justificativa para a alteração, ampliando via delegação aqueles que poderão agravar documentos públicos e impedir o amplo acesso à informação? Por que tal alteração configuraria um exemplo dos desmandos do Estado Pós-Democrático Direito?

A primeira pergunta requer a exposição dos dois lados da situação. Em resposta dada à imprensa no Jornal $O$ Globo, o autor do Decreto justifica as alterações a partir dos seguintes argumentos: "Você tem que ter um balanceamento entre segurança e transparência", e ainda: "O decreto, única e exclusivamente, ele diminui a burocracia na hora de você desqualificar alguns documentos sigilosos", também "Mourão argumentou que funcionários de nível mais baixo não poderão classificar o sigilo de documentos e que 'raríssimas' coisas são mantidas como ultrassecretas no país” (MARCELLO; BRITO, 2019).

Em nota, a Controladoria Geral da União ${ }^{5}$ também saiu em defesa do Decreto, alegando que apenas regulamentava uma previsão expressa

\footnotetext{
${ }^{5}$ A Lei de Acesso à Informação (Lei n. 12.527/2011), em seu artigo 27, §1 ${ }^{\circ}$, já previa a possibilidade de delegação da competência para classificação de informações em grau secreto e ultrassecreto. Essa delegação foi regulamentada pelo Decreto n. 7.724/2012, no âmbito do Poder Executivo federal, de maneira mais restritiva do que a própria lei, vetando a delegação. O Decreto n. 9.690, publicado hoje, resgata o espírito original da lei, permitindo a melhor operacionalização e simplificação da atuação do Estado. O decreto anterior optou pela restrição total como forma de regulamentação. Já o atual, fruto das experiências colhidas nos mais de seis anos de vigência, permite uma regulamentação mais voltada ao princípio da eficiência na administração pública. O novo decreto também ajusta a composição da Comissão Mista de Reavaliação de Informações (CMRI), que passa a ser composta por nove membros - e não mais dez, como anteriormente -
} 
do artigo $27, \S 1^{\circ}$, além de facilitar o processo, "visto que as mudanças ora propostas tem por intuito simplificar e desburocratizar a atuação do Estado", contribuindo, segundo a nota, para a transparência pública.

Entendimento contrário é bem exposto na Ação Popular movida contra o Decreto, com base na proteção do patrimônio moral e diante de uma inconstitucionalidade formal e material, conforme alega o autor da ação Carlos Alexandre Klomfahs (CONJUR, 2019). Basicamente, o argumento do vício formal refere-se a que, na prática, o Decreto, a despeito de afirmar que somente altera o Decreto anterior (Decreto n. 7.724/2012), na prática, altera no fundo e na forma a LAI, que somente poderia ser alterada obviamente por Lei ordinária, que, segundo o autor da ação, “[...] somente o Poder Legislativo poderia alterar, ampliando ou restringindo o conteúdo de uma lei por ele debatida, votada e aprovada interna corporis, modificando legitimamente as relações jurídicas no seio da sociedade". Materialmente afronta as diretrizes da LAI, tais como a observância da publicidade como preceito geral e do sigilo como exceção; divulgação de informações de interesse público, independentemente de solicitações; ao desenvolvimento da cultura de transparência na administração pública; desenvolvimento do controle social da administração pública (CONJUR, 2019).

Um dado é fato e expresso no novo Decreto: mudaram as regras para a classificação das informações, sendo que, a partir de agora, além do presidente, vice-presidente, ministros de Estado, comandantes das Forças Armadas e chefes de missões diplomáticas permanentes no exte-

refletindo a nova estrutura administrativa do Poder Executivo federal, em que os antigos ministérios do Planejamento, Desenvolvimento e Gestão e da Fazenda passaram a compor o Ministério da Economia. Quanto às alegações de que alterações relativas à classificação de informações trariam efeitos nocivos na aplicação da LAI, ressaltamos que tal assertiva não procede, visto que as mudanças ora propostas tem por intuito simplificar e desburocratizar a atuação do Estado. Destacamos, por exemplo, que tanto o Estado de Alagoas quanto o município de Belo Horizonte, que obtiveram maior pontuação em 2017 na Escala Brasil Transparente, e o Estado de Pernambuco, que obteve maior pontuação em 2018, também previram, em suas regulamentações da Lei de Acesso, tal possibilidade de delegação .Finalmente, ressaltamos que as mudanças ora realizadas são fruto de intensa discussão, desde 2018, entre a CGU e diversos atores, entre eles o Gabinete de Segurança Institucional, evidenciando a atuação integrada do Governo Federal na busca do aperfeiçoamento dos mecanismos de transparência pública (BRASIL, 2019). 
rior, os servidores comissionados e dirigentes de fundações, autarquias e empresas públicas também podem fazer essa classificação.

A segunda pergunta sobre por que tal alteração configuraria um exemplo dos desmandos do Estado Pós-Democrático Direito poderia ser respondida com outras: por que facilitar e ampliar as possibilidades de sigilo quanto à regra de transparência e acesso? Quem ganha com isso? Observando o contexto de forma fria e isolada, muitos diriam que é apenas mais uma regra de procedimento, chancelada pelo importante e pioneiro órgão da Administração Pública da União no combate à corrupção e em prol do controle social e transparência pública: a Controladoria Geral da União.

Exatamente por esses motivos que se entende ser um típico exemplo de Estado Pós-Democrático, pois, formalmente, segue-se com a LAI, as instituições públicas continuam funcionando normalmente, tais como a Controladoria Geral, e não há motivos para preocupações aparentes. No entanto, ampliar a pessoas comissionadas, servidores temporários, nomeados pelo próprio governo, a possibilidade de classificar como ultrassecretos seus próprios atos e tal medida ser dada por Decreto do Presidente em exercício significa menos transparência e não o contrário. Não há motivos para facilitar a obscuridade (ZOCKUN, 2004, p. 168).

Talvez essa dificuldade seja justamente o aspecto que possibilite que poucos documentos estejam agravados como ultrassecretos. Ademais, a justificativa é justamente, segundo a Controladoria Geral da União, o "aperfeiçoamento dos mecanismos de transparência pública", ou seja, em nome da transparência, menos transparência. Aparentemente tudo certo. O controle social está disponível, a LAI também, não fosse a possibilidade de ampliar o sigilo. Não nos parece que o controle social ganha algo com isso.

Surpreendente decisão foi a aprovação de projeto que susta os efeitos do decreto. A votação foi expressiva e uma forma de alerta ao governo que se pretende aprovação nos próximos projetos enviados, será necessário negociar com o Congresso. A expressividade da votação também é significativa. Foram 367 votos a favor, 57 contrários e três abstenções. 
Em 2020, no contexto da Pandemia de COVID-19, foi criada a MP n. 928/2020. Esta MP altera disposições da Lei n. 13.979, de 6 de fevereiro de 2020, inserindo o artigo $6^{\circ}$-B na referida Lei ${ }^{6}$. A Lei n. 13.979 é uma lei específica para políticas de enfrentamento à Pandemia de COVID-19. A especulação é a de que a motivação para a edição de tal MP residiria na necessidade de esconder exames médicos do Presidente da República, sendo que até o final da redação deste artigo não existia confirmação acerca do seu estado de saúde (REVISTA ISTOÉ, 2019). De todo modo, trata-se de medida com absurda restrição ao direito de controle da Administração Pública.

O STF, na medida cautelar da ADIN N. 6.351, na pessoa do Ministro Alexandre de Moraes, determinou a suspensão dos efeitos da Referida MP. Entre os argumentos levantados pelo ministro:

A participação política dos cidadãos em uma Democracia representativa somente se fortalece em um ambiente de total visibilidade e possibilidade de exposição crítica das diversas opiniões sobre as políticas públicas adotadas pelos governantes, como lembrado pelo

6 "Art. $6^{\circ}$-B Serão atendidos prioritariamente os pedidos de acesso à informação, de que trata a Lei n. 12.527, de 2011, relacionados com medidas de enfrentamento da emergência de saúde pública de que trata esta Lei.

$\S 1^{\circ}$ Ficarão suspensos os prazos de resposta a pedidos de acesso à informação nos órgãos ou nas entidades da administração pública cujos servidores estejam sujeitos a regime de quarentena, teletrabalho ou equivalentes e que, necessariamente, dependam de:

I - acesso presencial de agentes públicos encarregados da resposta; ou II - agente público ou setor prioritariamente envolvido com as medidas de enfrentamento da situação de emergência de que trata esta Lei.

$\S 2^{\circ}$ Os pedidos de acesso à informação pendentes de resposta com fundamento no disposto no $\S 1^{\circ}$ deverão ser reiterados no prazo de dez dias, contado da data em que for encerrado o prazo de reconhecimento de calamidade pública a que se refere o Decreto Legislativo $\mathrm{n}^{\mathrm{o}} 6$, de 20 de março de 2020.

$\S 3^{\circ}$ Não serão conhecidos os recursos interpostos contra negativa de resposta a pedido de informação negados com fundamento no disposto no $\S 1^{\circ}$.

$\S 4^{\circ}$ Durante a vigência desta Lei, o meio legítimo de apresentação de pedido de acesso a informações de que trata o art. 10 da Lei n. 12.527, de 2011, será exclusivamente o sistema disponível na internet.

$\S 5^{\circ}$ Fica suspenso o atendimento presencial a requerentes relativos aos pedidos de acesso à informação de que trata a Lei n. 12.527, de 2011”. (NR) 
JUSTICE HOLMES ao afirmar, com seu conhecido pragmatismo, a necessidade do exercício da política de desconfiança (politics of distrust) na formação do pensamento individual e na autodeterminação democrática, para o livre exercício dos direitos de sufrágio e oposição; além da necessária fiscalização dos órgãos governamentais, que somente se torna efetivamente possível com a garantia de publicidade e transparência.

Note-se, portanto, que, a despeito do simbolismo que envolve a efetividade do direito à transparência, há controvérsia judicial pelo menos no que toca aos seus grandes contornos. Além disso, os obstáculos a uma cidadania ativa no Brasil e zelosa com a coisa pública são de várias ordens, e o recorte pretendido nesta pesquisa está relacionado à formação da sociedade civil no Brasil, à marginalização dos movimentos sociais, à formação institucionalizada do controle social, ao acesso à informação como mecanismo mais formal do que social, levando a uma grande à descrença nas instituições.

\section{Conclusão}

A hipótese foi conclusiva no sentido de que o estabelecimento do neoliberalismo leva ao Estado de exceção. A presença conjunta de elementos culturais, econômicos e políticos do neoliberalismo necessariamente levam à exceção para que seja possível a estabilização do sistema.

O Estado de exceção atinge frontalmente o princípio democrático. Entre os postulados básicos da democracia, encontra-se a possibilidade de controle social. O controle social é importante elemento da Democracia e, como tal, também é atacado pelas normas de exceção. As normas de exceção, em conjunto com uma legislação simbólica, tornaram a publicidade mera formalidade - uma legislação simbólica. Esta legislação simbólica, assim, torna o controle social apenas uma espécie de mito - uma expectativa não realizada da modernidade.

O predomínio do neoliberalismo leva à impossibilidade de solidariedade social e consequente difusão de práticas de exceção. As práticas de exceção paulatinamente minam a democracia, impedimento o controle social, como foi o caso da edição do Decreto n. 9.690/2019. 


\section{Referências}

AGAMBEN, Giorgio. Estado de Excepção. Lisboa: Edições 70, 2010.

BAUMAN, Zigmund. O Mal-estar da Pós-Modernidade. Trad. Mauro Gama e Cláudia Gama. Rio de Janeiro: Jorge Zahar, 1998.

BRASIL. Controladoria Geral da União. Nota de esclarecimento

- Decreto n. 9.690/2019. Disponível em: http://www.cgu.gov.br/ noticias/2019/01/nota-de-esclarecimento-decreto-no-9-690-2019. Acesso em: 25 jan. 2019.

BRESSER-PEREIRA, Luiz Carlos. Modernidade neoliberal. Revista Brasileira de Ciências Sociais, [S.l.], v. 29, n. 84, fevereiro de 2014.

CASARA, Rubens R. R. Estado pós-democrático: neo-obscurantismo e gestão dos Indesejáveis. 2. ed. Rio de Janeiro: Civilização Brasileira, 2017.

CONJUR. Ação Popular. [2019]. Disponível em: https://www.conjur. com.br/dl/acao-popular-suspensao-decreto-modifica.pdf. Acesso em: 25 jan. 2019.

FRANKENBERG, Günter. Técnicas de Estado: perspectivas sobre o Estado de Direito e o Estado de Exceção. Tradução: Gercelia Mendes. São Paulo: UNESP, 2018.

GABARDO, Emerson. O jardim e a Praça para além do bem e do mal: uma antítese ao critério de subsidiariedade como determinante dos fins do Estado social. 2009. 409 p. Tese (Doutorado) - Universidade Federal do Paraná, Curitiba, 2009.

HACHEM, Daniel Wunder. A noção constitucional de desenvolvimento para além do viés econômico: reflexos sobre algumas tendências do Direito Público brasileiro. A\&C - Revista de Direito Administrativo \& Constitucional, Belo Horizonte, ano 13, n. 53, p. 133-168, jul.-set. 2013. LEVITSKY, Steven; ZIBLATT, Daniel. Como as democracias morrem. Rio de Janeiro: Zahar, 2018. 
LAVAL, Christian;’DARDOT, Pierre. A Nova Razão Do Mundo: ensaios sobre a sociedade neoliberal. São Paulo: Boitempo, 2016. MARCELLO, Maria Carolina; BRITO, Ricardo. Entrevista ao Jornal O Globo: Mourão e governo defendem decreto criticado por piorar transparência de dados. 24 de janeiro de 2019. Disponível em: https:// extra.globo.com/noticias/brasil/mourao-governo-defendem-decretocriticado-por-piorar-transparencia-de-dados-23398174.html. Acesso em: 16 abr. 2020.

MASON, Paul. Pós-capitalismo. São Paulo: Companhia das letras, 2018. NOHARA, Irene Patrícia. Reforma Administrativa e Burocracia: impacto da eficiência da Configuração do Direito Administrativo brasileiro. São Paulo: Atlas, 2012

REVISTA ISTOÉ. O que Bolsonaro esconde? Por Germano Oliveira, 27/03/20. Disponível em: https://istoe.com.br/o-que-bolsonaro-esconde/. Acesso em: $1^{\mathrm{o}}$ maio 2020

RUNCIMAN, David. Como a democracia chega ao fim. Tradutor: Sergio Laksman. São Paulo: Todavia, 2018.

SADDY, André. Formas de atuação e intervenção do Estado no brasileiro na economia. 3. ed. Rio de janeiro: Lumen Juris, 2018.

SADER, Emir; GENTILI, Pablo (org.). Pós-neoliberalismo: as políticas sociais e o Estado democrático: As políticas sociais e o Estado democrático. São Paulo: Paz e Terra, 2012.

SARMENTO, Daniel; SOUZA NETO, Cláudio Pereira de. Direito Constitucional: teoria, história e métodos de trabalho. Belo Horizonte: Fórum, 2013.

VALIM, Rafael. Estado de Exceção: a forma do jurídica do Neoliberalismo. São Paulo: Contracorrente, 2017.

ZOCKUN, Maurício. A separação dos poderes e o Judiciário como legislador positivo e negativo. Revista Trimestral de Direito Público (RTDP), [S.l.], n. 47, 2004. 
Caroline Müller Bitencourt é professora do Programa de Pós-Graduação, Mestrado e Doutorado da Universidade de Santa Cruz do Sul. Pós-Doutora em Direito pela Pontifícia Universidade Católica do Paraná. Doutora e Mestre em Direito pela UNISC. Especialista em Direito Público. Membro da Rede Docente Eurolatinoamericana de Direito Administrativo. Membro da Rede de Direito Administrativo Social. Coordenadora do Grupo de pesquisa Controle Social e Administrativo de Políticas Públicas e Serviço Público. Advogada.

E-mail: carolinemb@unisc.br

Endereço profissional: Av. Independência, n. 2.293, Universitário, Santa Cruz do Sul, RS. CEP: 96815-900.

ORCID: https://orcid.org/0000-0001-5911-8001

Janriê Rodrigues Reck é professor do Programa de Pós-Graduação stricto sensu da Universidade de Santa Cruz do Sul. Membro da Rede Docente Eurolatinoamericana de Direito Administrativo. Membro da Rede de Direito Administrativo Social. Procurador Federal.

E-mail: janriereck@gmail.com

Endereço profissional: Av. Independência, n. 2.293, Universitário, Santa Cruz do Sul, RS. CEP: 96815-900.

ORCID: https://orcid.org/0000-0001-9162-8941 